\title{
The Measurement of Teacher's Beliefs About Ability: Development of the Beliefs About Learning and Teaching Questionnaire
}

\author{
Christine V. Glenn \\ Near North District School Board
}

\begin{abstract}
The purpose of this article is to present the scale items, the statistical characteristics, and evidence of validity of the previously unpublished Beliefs about Learning and Teaching Questionnaire that examines elementary teachers' epistemological beliefs and their beliefs about learning and teaching in inclusive classrooms. In this study, 186 teachers completed the questionnaire. Reliability analysis yielded a Cronbach's alpha of .81. A factor analysis yielded four factors, including teachers' beliefs about ability and their preferences for teacher-controlled and student-centred instruction. To examine the relationship between teachers' beliefs about ability and their beliefs about disability and their responsibilities in working with students with disabilities, 36 teachers completed both the revised questionnaire and a semi-structured interview focused on beliefs and practices, the Pathognomonic-Interventionist Interview. The results suggest that teachers have varying beliefs about their roles and responsibilities in working with students with disabilities, and they provide evidence that these beliefs are related to their more widely held epistemological beliefs about ability. These range from a belief that ability is fixed and is unlikely to be influenced by learning and instruction, to a belief that ability is fluid and malleable, that it is increased by learning and therefore is responsive to instruction.
\end{abstract}

Among the factors addressed in the research on quality teaching are teachers' personally held beliefs about teaching and learning. Teachers' beliefs appear to underlie their decisions about how best to teach students, especially their beliefs about how students 
learn, how students' abilities and their environment outside the school setting influence the learning process, and teachers' roles and responsibilities in fostering student learning (Avramidis \& Kalyva, 2007; Black-Hawkins \& Florian, 2012; Brandes, McWhirter, Haring, Crowson, \& Millsap, 2012; Brownell, Jordan, \& Klingner, 2005; Ernst \& Rogers, 2009; Forlin, 2010; Jordan, Washington, Schwartz, \& Ahmed, 2005; Kahn \& Lewis, 2014; Pajares, 1992). Kagan (1992) stated, "The more one reads studies of teacher beliefs, the more one strongly suspects that this piebald of personal knowledge lies at the very heart of teaching" (p. 85), yet the difficulties of identifying and measuring teachers' beliefs have been noted (Black-Hawkins, 2010; Fives \& Buehl, 2012; Forlin, Earle, Loreman, \& Sharma, 2011; Kiely, Brownell, Lauterbach, \& Benedict, 2014; Pajares, 1992; Richardson, 1996; Schraw, 2013; Schraw \& Olafson, 2002; Verloop, Van Driel, \& Meijer. 2001).

Within the broad domain of belief are teachers' specific beliefs about the nature of disability and about their roles and responsibilities in responding to students in their classrooms with varying abilities and disabilities. Beliefs about disability range from the view that disability is a pathological state, internal to the student, fixed and immune to change, to the view that disability is a result of barriers created in the environment. These barriers may be, among other causes, physical, communicational, social, or emotional, but in any case, it is the responsibility of the teacher to circumvent or remove such barriers. These beliefs and their various attributions appear to impact teachers' decisions about practice, and therefore how they teach (Jordan, Lindsay, \& Stanovich, 1997; Jordan \& Stanovich, 2003; Jordan \& Stanovich, 2004; Loreman, Earle, Sharma, \& Forlin, 2007; Ruppar, Roberts, \& Olson, 2018; Silverman, 2007; Symeonidou \& Phtiaka, 2009). Empirical evidence suggests that teachers' beliefs about the nature of disability affect how they work with students both with and without special learning needs; the amount of time and effort they spend with students in their classrooms; and the types of instructional interactions and level of dialogue that they use, both in whole class expository instruction and in small group and one-to-one dialogues with students (Jordan \& Stanovich, 2003; Jordan, Kircaali-Iftar \& Diamond, 1993; McGee, 2004; Stanovich \& Jordan, 1998).

An outcome of this research has been to ask whether teachers' beliefs about disability are related to a broader set of beliefs about the nature of ability. Is it the case that teachers who hold a pathological view of disability also see ability as a fixed, stable condition of a learner, and not amenable to change? Conversely, do teachers who hold that a disability is the result of barriers to access also see ability as flexible, and in part shaped by the opportunity to learn?

\section{Beliefs About Disability}

Pathognomonic-Interventionist. Stanovich and Jordan (1998, 2002) and Jordan and Stanovich $(2003,2004)$ demonstrated that teachers differ in their beliefs about the nature of disability. About a quarter of the teachers interviewed described disability as a pathological state, internal to the student. These teachers viewed students with disabilities as beyond their influence as teachers and therefore beyond their instructional responsibility. Conversely, about $20 \%$ of teachers viewed disability as resulting from a barrier that had been created in part by the nature of the classroom, curriculum, and 
instruction, and that is amenable to being changed through learning when intervention (e.g., accommodations, instructional adaptation) is provided. These teachers viewed students with disabilities as a part of their instructional responsibility. The remaining teachers held beliefs rated between these two poles on a dimension that Stanovich and Jordan (1998) termed pathognomonic (naming the pathology) vs. interventionist (responsive to instructional intervention). The pathognomonic-interventionist (P-I) scale was developed over several years and is based on the verbatim descriptions of teachers about students in their classrooms as elicited through interviews. The P-I Interview is described below and elsewhere in this issue (Jordan, 2018b).

\section{Beliefs About Ability}

Entity-Increment. Stipek, Givvin, Samon, and McGyvers (2001) developed the Beliefs about Mathematics and Teaching Scale (BMTS) to examine teachers' beliefs that mathematics ability is an entity trait or an incrementally acquired characteristic of learners, and how such differences relate to teachers' preferred practices in teaching mathematics. Through factor analysis, Stipek et al. (2001) distinguished the EntityIncrement (E-I) factor consisting of six items. Teachers with entity beliefs hold that mathematics ability is a fixed, static, unchanging, internal characteristic of learners, unlikely to be amenable to instruction, and therefore unlikely to improve as a result of the teacher's instructional efforts. Teachers with increment beliefs about mathematics viewed ability as a fluid and malleable characteristic of learners, responsive to instructional and environmental influences (Dweck, 2000). Stipek et al. (2001) also demonstrated that teachers' beliefs about ability (as measured by the E-I scale) correlated negatively with teachers' self-rated preferences for teacher-controlled instruction, and correlated positively with preferences for student-centred instruction and with the use of intrinsic rather than extrinsic motivation for students (e.g., emphasizing relevant subject matter vs. grades). That is, teachers with a high score on the E-I scale, indicating a belief that ability is not fixed but is incrementally developed, also reported a preference for student-centred or student-led instruction. On the other hand, teachers who had a low E-I score, indicating a belief that ability is fixed and there is not much a teacher can do to change it, also expressed a preference for teacher-controlled and teacher-led instruction.

Although the original scale concerned beliefs about mathematics learning, the E-I scale of the BMTS show parallels to the P-I scale described above. At one end of each scale is a set of beliefs about either ability or disability as a fixed, stable, and internal characteristic of the learner, in what has been described as a "medical," "pathological," or "nativist" model. At the other end of each scale are beliefs about ability and disability as flexible and responsive to instructional influences in what has been termed the "social" or "environmental" model (Jordan \& Stanovich, 2004; Stanovich \& Jordan, 2002).

While the results of the Stipek et al. (2001) study are promising, they were based on a small sample of 21 teachers and are focused on beliefs about mathematics teaching and learning. With the permission of Stipek et al., Jordan et al. (2005) and Glenn (2007) completed the revision of the BMTS for regular classroom elementary school teachers to encompass literacy and science as well as mathematics. The questionnaire was renamed the Beliefs about Learning and Teaching Questionnaire (BLTQ). 
The goal of this research was to validate the factors in the BLTQ, in particular the EI factor and preferences for teaching associated with it, and to see how it related to the P-I variable of teachers' beliefs about disability. In the following sections, the development of the BLTQ is described, followed by an examination of the relationship between teachers' beliefs about the nature of ability and disability. The relationships between these variables is examined to determine whether there is a set of beliefs that link teachers' tacit understanding of the nature of both ability and disability in terms of viewing both as either fixed or flexible characteristics of learners, and how they relate to learning and instruction.

\section{Method}

\section{Development of the Beliefs About Learning and Teaching Questionnaire}

Participants. For the purposes of performing factor analysis and establishing the psychometric properties of the BLTQ, data were collected from 120 pre-service teachers and 66 practising teachers working in inclusive primary-, junior-, or intermediate-level classrooms. Of the 186 participants, 150 teachers were recruited as part of the current research to complete the BLTQ only, while 36 participants were recruited from a sample of teachers who completed the BLTQ and also participated in the P-I Interview.

Of the 186 participants, $152(81.7 \%)$ were attending teacher training programs or currently employed within a school board in southern Ontario. The remaining 34 participants $(18.3 \%)$ were employed as teachers in a school board in northeastern Ontario. As the BLTQ was completed anonymously, detailed demographic information was not available for all participants. Based on the data that were available, it was estimated that the majority of the sample was female, and the sample was approximately representative of the male-female ratio among full-time elementary school teachers in Ontario (junior kindergarten to Grade 8; see Giguère, 1999; King \& Peart, 1992; Wilson, 2004).

The BLTQ measures. The (BLTQ) is a 57-item measure of teachers' personal epistemological beliefs about the nature of ability and teachers' roles in fostering it (Table 1 contains examples of items; Jordan et al., 2005). This paper-and-pencil measure requires teachers to rate their agreement with statements about the nature of ability, instruction, and learning on a 6-point Likert-type scale. The items were originally developed based on content that was considered to be theoretically important to examining teachers' beliefs (i.e., entity-increment, traditional, and inquiry-oriented [or constructivist] beliefs) supporting the scale's content validity. In an initial analysis examining the psychometric properties of the BLTQ with 186 teachers and teacher candidates, the reliability using Cronbach's alpha was .69 (Jordan et al., 2005).

\section{The Pathognomonic-Interventionist Scale}

Participants. Among the 186 participants in the BLTQ sample were 36 teachers ( 7 males and 29 females) who, in addition to completing the BLTQ, provided P-I Interview data. The average length of teaching experience was 9.8 years, and ranged from two months to 30 years. Twenty-one teachers had no special education training. Of the remaining 15 teachers, seven had acquired further training through special education 
Additional Qualifications programs. Two participants reported qualifying as special education specialists, one teacher had completed Special Education Part 1, and four had completed Special Education Parts I and II. The remaining eight teachers reported participating in special education workshops and conferences.

While no data were collected directly from students, the parents or guardians of students in each of the classrooms of teachers who agreed to participate were provided with an information sheet and consent form. Only students whose parent or guardian provided signed consent forms were discussed during the interviews.

The P-I Interview measures. The confidential P-I Interviews (Jordan et al., 1997; McGee, 2001; Stanovich, 1994) were conducted one on one with teachers in a private room at their school, and took between 45 and 70 minutes.

As described by Jordan (Jordan \& Stanovich, 2004; Jordan, 2018b), the interview is conducted as a narrative of the teachers' experiences over the previous school year with two students: one who is exceptional with special educational needs, and the other who is at risk of academic failure. During the interview, teachers are requested to recount their experiences in working with the two students. Using a focused, non-directive interviewing method (Cohen \& Manion, 1989), interviews are conducted using a semistructured format. The interviews are audio-recorded, and the teachers' descriptions are later transcribed and coded to derive a quantitative measure of teachers' beliefs using a scoring form (Jordan \& Stanovich, 2004; Jordan, 2018b; Stanovich \& Jordan, 1998).

The statements of reasoning elicited through the interview are coded on 20 items using a 3-point scale. On each item, the pathognomonic perspective is scored as 1 (i.e., the teacher views learning difficulties as internal to the student and does not believe he or she is responsible for that student's instruction) and the interventionist perspective is scored as 3 (i.e., the teacher views a student's learning difficulties as amenable to instructional accommodations for which the teacher is responsible). The middle or mixed perspective is scored as 2 . The total score is the sum of the individual items, and reflects a bipolar dimension of beliefs about the characteristics of disability. Higher scores are reflective of interventionist beliefs, while lower scores suggest pathognomonic beliefs.

Following the interview, two additional ratings are completed by the interviewer. These holistic ratings are an extension of the main concepts of the P-I Interview and are completed after the rater has concluded the interview and after ratings for each of the 3point scales are completed. The additional ratings, Attribution and Responsibility require the interviewer to assign a holistic score to each teacher based on the responses he or she gave throughout the interview.

Attribution is a holistic rating (with a range of 1 to 5) of the cause to which the teacher most often attributes students' learning difficulties during the interview. Teachers who tend to attribute students' learning difficulties to characteristics internal to the students (e.g., ability, IQ, or exceptionality) receive a lower rating on this measure. Teachers who tend to attribute a student's learning difficulties to previous or current instructional or environmental factors receive a higher rating.

Responsibility is a holistic rating (with a range of 1 to 5) of the teacher's involvement and responsibility in providing instruction to students. Teachers who receive 
a lower rating on this measure are those who tend to use a student's exceptionality to justify their own exemption from responsibility in teaching that student. Teachers who receive a higher rating are those who tend to describe efforts to understand the student's disability and how it impacts other aspects of learning. These teachers describe taking a personal initiative in generating interventions and seeking services to meet students' individual academic needs.

The inter-rater reliability for the P-I Interview in previous studies ranged from .88 (Jordan et al., 1997) to .91 (McGee, 2001). Stanovich and Jordan (1998) reported a Cronbach's alpha of .89, and the mean Pearson correlation between the interview topics was .53. They also reported a principal components analysis of the 20 items yielding a first principal component that accounted for $36.9 \%$ of the total variance, replicating the findings reported earlier by Jordan-Wilson and Silverman (1991). Due to its high reliability, the total score created by summing the 20 items is used in this study.

The scores of the 36 teachers who participated in both the BLTQ and the P-I Interview provide an index of the concurrent validity of the measures of beliefs about ability and disability, together with an indication of preferred teaching approaches associated with either belief variable.

\section{Results}

\section{Development of the Beliefs about Learning and Teaching Questionnaire}

Item analysis. Item analysis was conducted on the 57 items to identify the items that contributed most to the homogeneity of the scale. Item means, standard deviations, the inter-item correlation matrix, and corrected item-total correlations were computed and examined. Descriptive statistics were calculated for each item, including frequencies for each response level on the 6-point scale. Item 15 ("Good instruction relates learning material to things students are interested in out of school") had the highest mean score of 5.35 , while item 9 ("There is usually only one way to solve a problem") had the lowest mean score of 1.46 .

According to Nunnally and Bernstein (1994), corrected item-total correlations near or greater than .20 , yet less than .70 are considered to be acceptable. Initially, serial calculations of corrected item-total correlation coefficients revealed that no items correlated higher than .50 with the total scale; however, 27 items correlated less than .20. These items were examined individually to determine their unique contribution to the scale, and 11 more items were eliminated due to a lack of homogeneity with the constructs of interest.

Following the removal of each item, reliability statistics were rerun, and the remaining items were re-evaluated. Further item analyses revealed the majority of the remaining 44 items to have corrected item-total correlations between .2 and .5. Items 16, 17, 18, 26, 28, $29,40,41$, and 46 correlated lower than .2 (range $=-.024$ to .175); however, they were retained during this phase of the analysis, as they contributed conceptually to the scale. Cronbach's alpha was estimated to be .79 for the remaining 44 items. 
An initial factor analysis of the 44 items based on the maximum likelihood estimation procedure was conducted. Examination of the unrotated solution revealed eight factors with variances greater than one (eigenvalue $>1$ ); however, examination of the scree plot suggested a three- or four-factor solution would best represent the data. Examination of the initial factor solution revealed the sixth and seventh factor to be comprised of two and three items respectively, and only one item loaded on the eighth factor. Furthermore, the item loadings revealed several items that loaded weakly on two or more factors. Using the same procedure outlined above, each item was scrutinized for its statistical and theoretical contribution to the scale. Through this process, an additional 14 items were tentatively removed from the scale. Cronbach's alpha of the remaining 30 items was .81 .

Factor analysis. Factor analysis of the remaining 30 items was performed to determine the nature and number of factors that could adequately explain the correlations among the responses to items representing teachers' beliefs. The range of inter-item correlations was $r=.265$ to .569 , indicating suitable item covariation, but not excessive redundancy.

Bartlett's test of sphericity and the Kaiser-Meyer-Olkin (KMO) measure of sampling adequacy were calculated to evaluate the strength of linear association among items and the appropriateness of the correlation matrix for the factor model. Bartlett's test of sphericity, based on a chi-square transformation of the determinant of the correlation matrix, was significant $\left(\chi^{2}=1522.91, p<.001\right)$. The KMO, an index that compares the magnitude of the observed correlations with the magnitude of the partial correlation coefficients (.82) and the goodness-of-fit statistic was large $\left(\chi^{2}=158.39, p=.87\right)$, which indicates that the factor model "fit" the data well. Moreover, each of the diagonals of the anti-image correlation matrix was above .7. Therefore, a factor analysis model was deemed appropriate to analyze the data, and it was expected that the remaining 30 items would share common factors.

Factor extraction. In determining the factor structure of the 30 items, both the orthogonal (varimax) and oblique (oblimin) rotated solutions were examined, which allowed for the comparison between the uncorrelated and correlated solutions. While the orthogonal rotation was given serious consideration, it was assumed that various aspects of teachers' beliefs would be related and it was decided that the factors would be best described as correlated. Therefore, the oblique rotation was selected for further analysis.

The rotated factor solution yielded six factors with eigenvalues greater than one; however, examination of the initial factor solution revealed the fifth factor to be comprised of two items (which both had split loadings on another factor), and only one item loaded on the sixth factor. Based on this, as well as through visual examination of the scree plot, it was determined that a four-factor solution would best represent the data. To test the assumption that the observed correlation between items was caused by the sharing of common factors, the residual correlation matrix was examined. All residual correlations were less than the recommended .10 for the four-factor extraction (Pett, Lackey, \& Sullivan, 2003; Tabachnick \& Fidell, 1983).

Factor rotation. The items included in a four-factor solution with oblimin rotation were adjusted until a solution was obtained that met specific criteria: (a) items loaded substantially $(\geq .3$ ) on only one factor; (b) each factor contained at least four items with 
loadings at or above .3; and (c) items loaded close to zero $(+.10$ or -.10$)$ on one other factor (Pett et al., 2003). Finally, the items that made up each factor were evaluated in terms of their theoretical contribution to that factor. This entire process resulted in the removal of 10 items from the scale.

\section{Table 1}

\section{Factor Loadings for the Rotated Factor Structure from Responses to Items on the BLTQ}

\begin{tabular}{|c|c|c|c|c|}
\hline Factors Items & A & B & C & D \\
\hline \multicolumn{5}{|l|}{ Factor A } \\
\hline 47. $\mathrm{S}$ & .794 & -.058 & -.074 & .067 \\
\hline $\begin{array}{l}\text { 13. Students cannot be counted upon to evaluate their own work } \\
\text { accurately. }\end{array}$ & .484 & -.131 & & -.074 \\
\hline $\begin{array}{l}\text { 48. It is important for students to complete assignments exactly as } \\
\text { the teacher planned. }\end{array}$ & .479 & -.032 & -.080 & -.111 \\
\hline $\begin{array}{l}\text { 43. In every class I find students to whom I just can't teach core } \\
\text { concepts. }\end{array}$ & .398 & .286 & .068 & -.061 \\
\hline $\begin{array}{l}\text { 25. It is important for teachers, not students, to direct the flow of a } \\
\text { lesson. }\end{array}$ & .336 & .114 & .046 & -.187 \\
\hline $\begin{array}{l}\text { 37. It is important for teachers to maintain compete control over } \\
\text { lessons. }\end{array}$ & .301 & .057 & -.140 & -.157 \\
\hline \multicolumn{5}{|l|}{ Factor B } \\
\hline $\begin{array}{l}\text { 34. The ability to learn is something people } h \\
\text { of and there isn't much they can do to ch }\end{array}$ & -.060 & .638 & -.048 & .016 \\
\hline $\begin{array}{l}\text { 1. The ability to learn is something that remains relatively fixed } \\
\text { throughout life. }\end{array}$ & -.124 & .581 & -.016 & -.100 \\
\hline $\begin{array}{l}\text { 44. There isn't much I can do about how much ability I have in } \\
\text { mathematics, science and language arts. }\end{array}$ & .215 & .467 & -.104 & -.066 \\
\hline $\begin{array}{l}\text { 35. There will always be some students who simply won't "get it" no } \\
\text { matter what I do. }\end{array}$ & .154 & .454 & -.055 & .011 \\
\hline \multicolumn{5}{|l|}{ Factor C } \\
\hline $\begin{array}{l}\text { 32. To assess students' understanding of a core concept, it is } \\
\text { important to observe and listen to their conversations as they } \\
\text { work. }\end{array}$ & .114 & -.111 & .608 & .215 \\
\hline 31. Good teachers give students choices in their learning tasks. & -.064 & .098 & .564 & .018 \\
\hline $\begin{array}{l}\text { 16. In core subject } \\
\text { examples. }\end{array}$ & .025 & -.003 &.$\overline{.535}$ & -.051 \\
\hline $\begin{array}{l}\text { 15. Good instruction relates learning material to things students are } \\
\text { interested in outside of school. }\end{array}$ & .017 & .206 &.$\underline{.526}$ & -.145 \\
\hline $\begin{array}{l}\text { 40. It doesn't matter whether students get the right answer as long } \\
\text { as they understand the concepts inherent in the problem. }\end{array}$ & -.062 & .045 & .383 & -.010 \\
\hline $\begin{array}{l}\text { 17. Concerns about getting the correct answer are likely to interfere } \\
\text { with concept development and learning. }\end{array}$ & -.134 & .012 & .302 & .084 \\
\hline \multicolumn{5}{|l|}{ Factor D } \\
\hline $\begin{array}{l}\text { 56. Giving grades on assignments is a good strategy for getting } \\
\text { students to work. }\end{array}$ & .073 & -.115 & .049 & $\underline{-.765}$ \\
\hline $\begin{array}{l}\text { 55. The more students are concerned about grades and } \\
\text { performance, the more they learn. }\end{array}$ & -.016 & .166 & -.163 & $\underline{-.667}$ \\
\hline 21. All of my students would do well if they worked hard. & .06 & .102 & -.109 & -.420 \\
\hline $\begin{array}{l}\text { 38. Students who produce correct answers have a good } \\
\text { understanding of core concepts. }\end{array}$ & .262 & .147 & .006 & -.337 \\
\hline
\end{tabular}


Bartlett's test of sphericity, based on chi-square transformation of the determinant of the correlation matrix, was significant $\left(\chi^{2}=868.66, p<.000\right)$. The KMO $(.82)$ and the goodness-of-fit statistic were large $\left(\chi^{2}=129.80, p=.18\right)$. In addition, each of the diagonals of the anti-image correlation matrix was above .7. The factor loadings from the pattern matrix for the rotated four-factor solution from responses to items on the BLTQ are displayed in Table 1.

Factor interpretation. Once the factors and their items were determined to be statistically and conceptually sound, it was possible to name the factors.

Factor A had an eigenvalue of 5.05 and explained $25.27 \%$ of the variance. Similar to the results of the principal components factor analysis by Stipek et al. (2001), this factor was defined by items that relate to traditional teaching methods (e.g., "It is important for teachers, not students, to direct the flow of a lesson"; see Table 1). As illustrated by Stipek et al. (2001), traditional educators conduct lessons during which a new procedure is introduced, and the necessary steps to solve problems using the procedure are provided, followed by exercises to practise the procedure. Therefore, learning is controlled by the teacher, allowing for little flexibility in how students acquire knowledge and skills. As the items that loaded on Factor A reflect these beliefs, it was named "Teacher-Controlled Instruction." Higher scores on this variable represent beliefs that are more traditional (i.e., the role of the teacher is to transmit information to students, controlling what and how students learn).

Factor B had an eigenvalue of 1.76 and accounted for $8.82 \%$ of the variance. Stipek et al. (2001) found evidence of a range of views of ability among a sample of 21 sixthgrade teachers. Consistent with the findings of Stipek et al. (2001), Factor B is comprised of four items that reflect teachers' beliefs about ability (e.g., "The ability to learn is something that remains fixed throughout life"). As described by Dweck (2000), ability can be viewed as a fixed, stable trait that affects learning and performance in a variety of subject areas. This view of ability is referred to as an entity view. Ability can also be viewed from another perspective, where it is considered to be the result of good teaching, study, and practice (Dweck, 2000). From this perspective, known as an increment view, ability can increase with effort. Based on the content of the items that loaded on Factor B, it was originally labeled "Increment-Entity" (where lower scores represent incremental beliefs and higher scores represent entity beliefs); however, in order to remain consistent with the P-I measure (where lower scores represent pathognomonic beliefs and higher scores represent interventionist beliefs), each item in this factor was reverse-scored to create the Entity-Increment factor. By reversing the items, lower scores now represent entity beliefs where higher scores represent incremental beliefs.

Factor $\mathrm{C}$ had an eigenvalue of 1.57 and accounted for $7.83 \%$ of the variance. Items loading at or greater than .30 on this factor (e.g., "Good teachers give students choices in their learning tasks") relate to the belief that the role of the teacher is not simply to transmit information to students; rather, teachers are to provide support and guidance to their students through activities that require the students to gather and apply information, reason and be creative, and discover and communicate ideas (Ball, 1993; Kaplowitz, 2012; Odom, Stoddard, \& LaNasa, 2007; Rogers, Lyon, \& Tausch, 2014; Wood, Cobb, $\&$ Yackel, 1991). Higher scores on this factor reflect beliefs that teaching should allow 
for flexibility in instruction and freedom for students to participate in the learning process. Emphasis is placed on the student and the understanding of concepts rather than on producing correct responses. Based on the content of these items, this factor was named "Student-Centred Instruction."

The final factor, D, had an eigenvalue of 1.19 and accounted for $5.94 \%$ of the variance. This factor was interpreted to primarily reflect teachers' beliefs about students meeting certain standards (e.g., "Giving grades is a good strategy for getting students to work") and was subsequently named "Attaining Standards." Higher scores represent more emphasis by the teacher on producing correct results and the use of grades (or external rewards) as motivation for students to meet set expectations.

Table 2 presents the descriptive statistics, between-factor correlations, and Cronbach's alpha for the four generated subscales of the BLTQ. Pearson correlations between the subscales ranged from .50 (between Teacher-Controlled Instruction and Attaining Standards) to -.42 (Student-Centred Instruction and Teacher-Controlled Instruction), supporting the notion that the BLTQ factors are correlated, yet relatively distinct dimensions of teachers' beliefs.

For new instruments, a minimum reliability of .7 is recommended (Aron \& Aron, 1994; DeVellis, 1991; George \& Mallery, 2003), where a reliability of .6 is considered to be adequate. As shown in Table 2, all four factors had an adequate degree of internal consistency.

Table 2

Factor Correlations and Cronbach's Alpha for the BLTQ

\begin{tabular}{|c|c|c|c|c|c|c|c|}
\hline Factor & $\begin{array}{l}\text { Teacher- } \\
\text { Controlled } \\
\text { Instruction }\end{array}$ & $\begin{array}{c}\text { Entity- } \\
\text { Increment }\end{array}$ & $\begin{array}{l}\text { Student- } \\
\text { Centred } \\
\text { Instruction }\end{array}$ & $\begin{array}{l}\text { Attaining } \\
\text { Standards }\end{array}$ & $M$ & $S D$ & $\begin{array}{c}\text { Cronbach's } \\
\text { Alpha }\end{array}$ \\
\hline $\begin{array}{l}\text { Teacher- } \\
\text { Controlled } \\
\text { Instruction } \\
(6 \text { items) }\end{array}$ & 1.00 & & & & $18.14^{\mathrm{a}}$ & 4.39 & .71 \\
\hline $\begin{array}{l}\text { Entity- } \\
\text { Increment } \\
\text { (4 items) }\end{array}$ & .37 & 1.00 & & & $9.90^{\mathrm{b}}$ & 3.16 & .63 \\
\hline $\begin{array}{l}\text { Student- } \\
\text { Centred } \\
\text { Instruction } \\
(6 \text { items) }\end{array}$ & -.42 & -.26 & 1.00 & & $28.10^{c}$ & 3.42 & .64 \\
\hline $\begin{array}{l}\text { Attaining } \\
\text { Standards } \\
\text { (4 items) }\end{array}$ & -.50 & -.39 & -.33 & 1.00 & $15.85^{\mathrm{d}}$ & 4.25 & .71 \\
\hline
\end{tabular}

Note. a. Range $=6$ to 36 ; b. Range $=4$ to 24 ; . Range $=6$ to 36 ; d. Range $=4$ to 24 


\section{The Relationship Between Beliefs About Ability and Disability}

Following completion of the factor analysis, the relationship between the E-I factor of the BLTQ and teachers' beliefs about their roles and responsibilities in working with students with disabilities (P-I) was examined. Examination of teachers' beliefs about ability (E-I) and disability (P-I) revealed a moderate, positive correlation, $r(32)=.37$, $p<.05$. That is, teachers who held more incremental beliefs (i.e., they viewed ability as flexible and amenable to teaching, as represented by higher scores on the E-I factor), tended to hold more interventionist beliefs about their roles and responsibilities in working with students with disabilities. Conversely, the correlation between E-I and P-I implies that those teachers who held more entity beliefs (i.e., they viewed ability as fixed and not amenable to teaching, as represented by lower scores on the E-I factor), had lower scores on the P-I Interview.

Examination of the relations between the holistic scores generated from the P-I Interview and the E-I factor revealed significant positive correlations between Attribution and E-I, $r(32)=.48, p<.01$, and Responsibility and E-I, $r(32)=.54, p<.01$.

The correlation between teachers' beliefs about their roles and responsibilities in working with students with disabilities and the remaining three factors derived through factor analysis of the BLTQ were examined. A significant positive correlation was found between Student-Centred Instruction and P-I, $r(32)=.44, p<.05$, and between Attaining Standards and P-I, $r(32)=-.54, p<.001$. The correlation between P-I and TeacherControlled Instruction was not significant.

Examination of the Attribution and Responsibility subscores of the P-I and the three remaining BLTQ factors revealed a strong negative correlation between Attribution and Attaining Standards, $r(32)=-.55, p<.001$, and between Responsibility and Attaining Standards, $r(32)=-.57, p<.001$. While no significant correlations were found between Attribution and Student-Centred Instruction, or between Attribution and Responsibility, or Teacher-Controlled Instruction, a moderate positive relation was found between Responsibility and Student-Centred Instruction, $r(32)=.46, p<.01$.

\section{Discussion}

A factor analysis using the maximum-likelihood-estimation procedure with oblique rotation was performed on the 57 items of the BLTQ. A sample of 186 teachers provided data for this aspect of the study. As described earlier, several of the original items did not contribute meaningfully (statistically or conceptually) to the scale and were subsequently removed (see Table 1). Several of the teachers who completed the BLTQ had concerns regarding the wording of some of the scale items. For example, difficulty interpreting item 21 was reported ("All of my students would do well if they worked hard"), as it was unclear whether the item referred to the student performing well in relation to his or her own potential or in relation to his or her classmates.

Teacher-Controlled Instruction was the strongest factor and explained the greatest percentage of variance $(25.27 \%)$. Similar to the Teacher Control factor found by Stipek et al. (2001), the six items that made up this factor related to the notion that learning is 
controlled by the teacher. Higher scores on the Teacher-Controlled Instruction factor represent more traditional beliefs about teaching and reflect the belief that the teacher must be in control of his or her students' learning, allowing for little flexibility in how students acquire knowledge.

The Student-Centred Instruction factor was made up of several items that Stipek et al. (2001) labeled Math as Operations. Higher scores on this factor reflect beliefs that teaching should allow for flexibility in instruction and freedom for students to participate in the learning process. Unlike Teacher-Controlled Instruction, the role of the teacher is to guide the learning process rather than to transmit knowledge. Emphasis is placed on the student and the understanding of concepts rather than on producing correct responses.

The Attaining Standards factor was similar to Stipek et al.'s (2001) Extrinsic Motivation factor, which contained items reflecting the use of extrinsic rewards and grades as effective strategies for motivating students to engage in learning (and at the opposite end, students' willingness to work hard on interesting and challenging tasks).

Of primary interest in this study was the E-I factor, which was represented by items that tap participants' beliefs about ability (see Table 1). The four items that loaded on the E-I factor were among the items that loaded on Stipek et al.'s (2001) Entity Theory. The presence of the E-I factor in the revision of the BLTQ supports the notion that teachers' beliefs about ability exist on a continuum that ranges from the view that ability is fixed and stable, limiting the effectiveness of effort, to the view that ability is flexible, responsive to teaching, study, and practice as well as to the amount of effort put in (Dweck, 2000; Levy \& Dweck, 1998).

The second aspect of the current research was to expand the variable of teachers' beliefs by establishing the correlation between teachers' predominant beliefs about their roles and responsibilities in working with students with disabilities and their more widely held epistemological frameworks, which contain beliefs, preconceptions, and propositional knowledge about the nature of knowledge and learning in all students. Of primary interest was the relationship between teachers' beliefs about their roles and responsibilities in working with students with disabilities and their beliefs about ability. Within the sample of 36 teachers who participated in all aspects of the study, there was a significant positive correlation between their beliefs about ability (E-I) and disability (PI). These results suggest that those teachers who held more incremental beliefs tended to hold more interventionist beliefs about their roles and responsibilities in working with students with disabilities. Conversely, the correlation between E-I and P-I implies that those teachers who held more entity beliefs had lower scores on the P-I Interview, which represent the view that the teaching of students with disabilities is not the responsibility of the regular classroom teacher, but instead falls under the domain of special education (Jordan \& Stanovich, 2003; Jordan, 2018a).

When examining the correlation between the P-I subscores of Responsibility and Attribution and the E-I score, a significant correlation was found between Attribution and E-I, suggesting that teachers who tended to attribute a student's learning difficulties to characteristics internal to the student (e.g., ability, IQ, or exceptionality) held more entity beliefs as measured by the E-I factor. The significant correlation between Responsibility 
and E-I suggests that teachers who tended to use a student's exceptionality as justification for not being responsible for the instruction of that student held more entity beliefs.

While it is important to reiterate that Stipek et al.'s (2001) sample was small $(N=21)$, the results of the current study support their findings. Even with the removal of several low-loading items from the scale the factor structure was similar to the original scale from which it was developed (Stipek et al., 2001), supporting the possibility that beliefs about ability, teaching, and student learning are consistent across samples of teachers.

In this research, exploratory factor analysis has aided in defining the internal structure of the BLTQ items and grouped these items into four factors. All four factors of the BLTQ met the minimum standard. As the magnitude of the reliability coefficient is affected by the number of items in the scale, further development of the BLTQ should include the addition of new, conceptually sound items designed to strengthen each subscale.

While the BLTQ appears to have sufficient validity, exploratory factor analysis is but one statistical method of explicating constructs for validity. Other components of construct validity - specifically, convergent and discriminant validity - must be evaluated through further development of the scale (Pett et al., 2003). As the replicability of the four-factor solution needs to be determined, subsequent phases in the development of the BLTQ will require the administration of the revised version of the scale to a larger sample of teachers followed by confirmatory factor analysis.

While there is room for development (see Lanterman, 2018, and Specht et al., 2018, this issue), these results indicate preliminary supportive evidence for the use of the BLTQ in research addressing teachers' beliefs about ability, teaching, and learning. Assessing teachers' beliefs through the use of a valid and reliable assessment tool can provide insight into specific beliefs about ability, teaching, and learning that could aid in planning, implementing, and evaluating teaching practices, and could contribute to the existing body of knowledge about effective teaching in inclusive classrooms.

With regard to the relationship between teachers' beliefs about ability and disability, the results of the current study support previous research that suggests teachers have varying beliefs about students with disabilities and provides evidence that teachers' beliefs about their roles and responsibilities in working with students with disabilities are related to their more widely held beliefs about ability. The results also provide preliminary evidence of an underlying construct of epistemological beliefs that exists among teachers, which the E-I factor is able to tap. The resulting correlations are modest, and suggest that further research is warranted to examine how teachers form epistemological beliefs, how their beliefs influence who they teach and how they go about it, what characteristics of learners are contributing to the beliefs, and how beliefs can be modified. Furthermore, these results contribute to the literature (e.g., Pajares, 1992; Schraw, 2013; Schraw \& Sinatra, 2004) supporting the notion of an overall epistemological understanding that teachers bring to the teaching profession, which may have tremendous implications for how teachers develop their skills and practice as educators. 


\section{References}

Aron, A., \& Aron, E. N. (1994). Statistics for psychology. Englewood Cliffs, NJ: Prentice Hall.

Avramidis, E., \& Kalyva, E. (2007). The influence of teaching experience and professional development on Greek teachers' attitudes towards inclusion. European Journal of Special Needs Education, 22, 367-389.

Ball, D. (1993). With an eye toward the mathematical horizon: Dilemmas of teaching elementary school mathematics. Elementary School Journal, 93, 373-397.

Black-Hawkins, K. (2010). The framework for participation: A research tool for exploring the relationship between achievement and inclusion in schools. International Journal of Research \& Method in Education, 33, 21-40.

Black-Hawkins, K., \& Florian, L. (2012). Classroom teachers' craft knowledge of their inclusive practices. Teachers and Teaching, 18, 567-584.

Brandes, J. A., McWhirter, P. T., Haring, K. A., Crowson, M. H., \& Millsap, C. A. (2012). Development of the indicators of successful inclusion scale (ISIS): Addressing ecological concerns. Teacher Development, 16, 463-488.

Brownell, M., Jordan, A., \& Klingner, J. (2005, August). The quality of instruction in inclusive and special education classrooms. Paper presented at the International Special Education Conference, Glasgow, Scotland.

Cohen, L., \& Manion, L. (1989). Research methods in education. New York, NY: Routledge.

DeVellis, R. F. (1991). Scale development: Theory and applications. Newbury Park, CA: Sage Publications.

Dweck, C. S. (2000). Self-theories: Their role in motivation, personality and development. Philadelphia, PA: Taylor and Francis.

Ernst, C., \& Rogers, M. R. (2009). Development of the Inclusion Attitude Scale for high school teachers. Journal of Applied School Psychology, 25, 305-322.

Fives, H., \& Buehl, M. M. (2012). Spring cleaning for the "messy" construct of teachers' beliefs: What are they? Which have been examined? What can they tell us? In Harris, K. R., Graham, S., \& Urdan, T. (Eds.), APA educational psychology handbook: Individual differences and cultural and contextual factors (vol. 2, pp. 471-499). Washington, DC: American Psychological Association.

Forlin, C. (2010). Re-framing teacher education for inclusion. In Forlin, C. (Ed.), Teacher education for inclusion: Changing paradigms and innovative approaches (pp. 3-10). Abingdon, UK: Routledge.

Forlin, C., Earle, C., Loreman, T., \& Sharma, U. (2011). The Sentiments, Attitudes, and Concerns about Inclusive Education Revised (SACIE-R) scale for measuring pre-service teachers' perceptions about inclusion. Exceptionality Education International, 21, 50-65.

George, D., \& Mallery, P. (2003). SPSS for Windows step by step: A simple guide and reference (4th ed.). Boston, MA: Allyn \& Bacon.

Giguére, D. (1999). Gender gap widening among Ontario teachers. Professionally speaking, 2009 (June). Retrieved July 19, 2006 from https://professionallyspeaking.oct.ca/june_1999/gap.htm

Glenn, C. V. (2007). The relationship between epistemological beliefs and effective teaching practices among elementary school teachers (Unpublished Ph.D. dissertation). University of Toronto, Toronto, ON.

Jordan, A. (2018a). The Supporting Effective Teaching project: 1. A model of factors influencing student success in inclusive elementary classrooms. Exceptionality Education International, $28(3), 10-27$. 
Jordan, A. (2018b). The Supporting Effective Teaching project: 2. The measures. Exceptionality Education International, 28(3), 28-50.

Jordan, A., Kircaali-Iftar, G., \& Diamond, C. T. P. (1993). Who has a problem, the student or the teacher? Differences in teachers' beliefs about their work with at-risk and integrated exceptional students. International Journal of Disability, Development and Education, 40, 45-62.

Jordan, A., Lindsay, L., \& Stanovich, P. J. (1997). Classroom teachers' interactions with students who are normally achieving, at-risk and exceptional. Remedial and Special Education, 18, 82-93.

Jordan, A., \& Stanovich, P. J. (2003). Teachers' personal epistemological beliefs about students with disabilities as indicators of effective teaching practices. Journal of Research in Special Educational Needs [Online], 3(1). doi:10.1111/j.1471-3802.2003.00184.x

Jordan, A., \& Stanovich, P. J. (2004). The beliefs and practices of Canadian teachers about including students with special needs in their regular elementary classrooms. Exceptionality Education Canada, 14, 25-46.

Jordan, A., Washington, D., Schwartz, E., \& Ahmed, Q. (2005, May). Effective teaching in inclusive classrooms. Paper presented to the Canadian Society for Studies in Education, London, ON.

Jordan-Wilson, A., \& Silverman, H. (1991). Teachers' assumptions and beliefs about the delivery of services to exceptional children. Teacher Education and Special Education, 14, 198-206.

Kagan, D. M. (1992). Implications of research on teacher belief. Educational Psychologist, 27, 65-90.

Kahn, S., \& Lewis, A. R. (2014). Survey on teaching science to K-12 students with disabilities: Teacher preparedness and attitudes. Journal of Science Teacher Education, 25, 885-910.

Kaplowitz, J. R. (2012). Transforming information literacy instruction using learner-centered teaching. New York, NY: Neal-Schuman Publishers.

Kiely, M. T., Brownell, M. T., Lauterbach, A. A., \& Benedict, A. E., (2014). Teacher beliefs about students with special needs and inclusion. In H. Fives \& M. G. Gill, (Eds.), International handbook of research on teacher beliefs (pp. 475-490). New York, NY: Routledge.

King, A. J., \& Peart, M. J. (1992). Teachers in Canada: Their work and quality of life. Ottawa, ON: Canadian Teachers' Federation.

Lanterman, C. S. \& Applequist, K. (2018). Pre-service teachers' beliefs about disability after training in Universal Design for Learning. Exceptionality Education International, 28(3), 102-121.

Levy, S. R., \& Dweck, C. S. (1998). Trait- versus process-focused social judgment. Social Cognition, 16, 151-172.

Loreman, T., Earle, C., Sharma, U., \& Forlin, C. (2007). The development of an instrument for measuring pre-service teachers' sentiments, attitudes and concerns about inclusive education. International Journal of Special Education, 22, 150-159.

McGee, M. R. (2001). Measuring effective teaching in inclusive classrooms. (Unpublished Master's thesis). University of Toronto (OISE), Toronto, ON.

McGee, M. R. (2004). Teacher and school variables associated with the academic and social outcomes of students with special needs in general education classrooms. (Unpublished doctoral dissertation). University of Toronto (OISE), Toronto, ON.

Nunnally, J. C., \& Bernstein, I. H. (1994). Psychometric theory (3rd ed.). New York, NY: McGraw-Hill.

Odom, A. L., Stoddard, E. R., \& LaNasa, S. M. (2007). Teacher practices and middle-school science achievements. International Journal of Science Education, 29, 1329-1346.

Pett, M. A., Lackey, N. R., \& Sullivan, J. J. (2003). Making sense of factor analysis: The use of factor analysis for instrument development in health care research. Thousand Oaks, CA: Sage Publications. 
Pajares, F. (1992). Teachers' beliefs and educational research: Cleaning up a messy construct. Review of Educational Research, 62, 307-332.

Richardson, V. (1996). The role of attitudes and beliefs in learning to teach. In J. Sikula (Ed.), Handbook of research on teacher education (pp. 102-119). New York, NY: Macmillan.

Rogers, C. R., Lyon, H. C., \& Tausch, R. (2014). On becoming an effective teacher. London, UK: Routledge.

Ruppar, A. L., Roberts, C. A., \& Olson, A. J. (2018). Is it all about loving the kids? Perceptions about expertise in special education. Teaching and Teacher Education, 71, 319-328.

Schraw, G. (2013). Conceptual integration and measurement of epistemological and ontological beliefs in educational research. ISRN Education, 2013, 1-19. doi:10.1155/2013/327680

Schraw, G. \& Olafson, L. J. (2002). Teachers' epistemological world views and educational practices. Issues in Education, 8, 99-148.

Schraw, G., \& Sinatra, G., (2004). Epistemological development and its impact on cognition in academic domains. Contemporary Educational Psychology, 29(2), 95-206.

Silverman, J. C. (2007). Epistemological beliefs and attitudes toward inclusion in pre-service teachers. Teacher Education and Special Education, 30, 42-51.

Specht, J. A., \& Metsala, J. L. (2018). Predictors of teacher efficacy for inclusive practice in preservice teachers. Exceptionality Education International, 28(3), 67-82.

Stanovich, P. J. (1994). Teachers' sense of efficacy, beliefs about practice and teaching behaviors as predictors of effective inclusion of exceptional and at-risk students (Unpublished doctoral dissertation). University of Toronto, Toronto, ON.

Stanovich, P. J., \& Jordan, A. (1998). Canadian teachers' and principals' beliefs about inclusive education as predictors of effective teaching in heterogeneous classrooms. Elementary School Journal, 98, 221-238.

Stanovich, P. J., \& Jordan, A. (2002). Preparing general educators to teach in inclusive classrooms: Some food for thought. The Teacher Educator, 37, 173-185.

Stipek, D. J., Givvin, K. B., Samon, J. M., \& McGyvers, V. L. (2001). Teachers' beliefs and practices related to mathematics instruction. Teaching and Teacher Education, 17, 213-226.

Symeonidou, S., \& Phtiaka, H. (2009). Using teachers' prior knowledge, attitudes, and beliefs to develop in-service teacher education courses for inclusion. Teaching and Teacher Education, $23,543-550$.

Tabachnick, B. G., \& Fidell, L. S. (1983). Using multivariate statistics. New York, NY: Harper and Row.

Verloop, N., Van Driel, J., \& Meijer, P. (2001). Teacher knowledge and the knowledge base of teaching. International Journal of Educational Research, 35, 441-461.

Wilson, D. (2004). Registrar's report: A few (more) good men. Professionally Speaking, 2004 (March). Retrieved from https://professionallyspeaking.oct.ca/march_2004/registrar.asp

Wood, T., Cobb, P., \& Yackel, E. (1991). Change in teaching mathematics: A case study. American Educational Research Journal, 28, 587-/616.

\section{Author's Note}

Correspondence concerning this article should be addressed to Christine Glenn, 15 Janey Avenue, North Bay, ON, P1C 1N1, Canada. Email: christine.glenn@nearnorthschools.ca 